\title{
PERFORMA SAMBUNGAN BALOK PRECAST SEDERHANA DENGAN SISTIM DOUBLE LAPSPLICES MIDDLE WET JOINT DI MOMEN MAKSIMUM
}

\author{
A.Rudi Hermawan ${ }^{1}$ dan Eka $\mathrm{SM}^{2}$ \\ ${ }^{1,2}$ Politeknik Negeri Jakarta Jurusan Teknik Sipil,Jalan Prof.Dr GA Siwabessy Kampus Baru UI Depok \\ 16425 \\ $\nabla_{e-m a i l}:$ arudihermawan@gmail.com
}

\begin{abstract}
This research about connection of precast simple beam with double lapsplices middle wet joint system was finished with comparing of flexure strength between precast beam with connection at meddle span (middle wet joint) and conventional beam. Metode of testing was applicated only one point loading at the middle of beam.Performance of flexure strength of precast beam with connection at meddle span (middle wet joint) is better than conventional beam, can be proved to curve of deflection - load between conventional beam (1 and 2) with precast beam with connection at middle span (middle wet joint 1 and 2). Base on that curve, can be known that precast beam with connection at meddle span (middle wet joint 1) have deflection $10 \mathrm{~mm}$ at 151,8 $\mathrm{KN}$ and precast beam with connection at meddle span (middle wet joint 2) have deflection16 $\mathrm{mm}$ at 169,2 $\mathrm{KN}$ and conventional beam 1 have deflection $47 \mathrm{~mm}$ at 145,5 $\mathrm{KN}$ and conventional beam 2 have deflection $40 \mathrm{~mm}$ at 144,7 KN. Conclusion this research is precast beam has perform better than convensional beam.
\end{abstract}

Keywords : Precast, deflection, connection

\begin{abstract}
Abstrak
Pada penelitian sambungan balok pracetak sederhana dengan sistm double lapsplices middle wet joint pada balok pracetak ini telah dihasilkan suatu perbandingan kekuatan lentur antara balok pracetak dengan sambungan di tengah bentang (middle wet joint) dengan balok konvensional. Metoda pengujian yang diterapkan adalah pembebanan satu titik pada balok di tengah bentang.Dari hasil yang ada terlihat bahwa performa balok pracetak yang disambung di tengah bentang dengan sistim middle wet joint dibandingkan dengan balok konvensional adalah lebih baik, hal itu dibuktikan pada kurva hubungan lendutan-beban antara benda uji konvensional 1 dan benda uji konvensional 2 dengan benda uji pracetak 1 dan benda uji precast 2. Dari kurva yang ada diketahui bahwa benda uji balok pracetak 1 mempunyai lendutan $10 \mathrm{~mm}$ pada beban 151,8 KN dan benda uji precast 2 mempunyai lendutan $16 \mathrm{~mm}$ pada beban 169,2 KN sedangkan pada benda uji konvensional 1 mempunyai lendutan 47 mm pada beban 145,5 KN dan benda uji 2 mempunyai lendutan $40 \mathrm{~mm}$ pada beban 144,7.KN. Kesimpulan dari penelitian ini adalah bahwa balok precast mempunyai performa yang lebih baik dibandingkan balok konvensional.
\end{abstract}

Kata kunci :Pracetak, lendutan, sambungan

\section{Pendahuluan}

Seiring dengan pesatnya perkembangan dalam dunia kontruksi bangunan, sangatlah perlu kiranya diadakan suatu bentuk inovasi di bidang kontruksi tersebut. Penelitian terdahulu telah banyak memberikan kemudahankemudahan dalam pelaksanaan kontruksi bangunan, bahkan sampai dapat meminimalkan biaya kontruksi.
Penelitian dan penemuan dalam bidang pelakasanaan dan bidang struktur banyak dijumpai di Jurnal ACI (American Concrete Institute) ataupun Jurnal PCI (Precast/ prestressed Concrete Institute ). Salah satu bagian yang terpenting dalam struktur bangunan precast adalah kemudahan dalam pelaksanaan kontruksi bangunan (erection) dengan menggunakan sambungan (joint) pada elemen balok 
atau kolom dalam stuktur bangunan. Seperti penelitian yang telah dilakukan oleh Jay E Ochs dan M.R.Ehsani mengenai sistim sambungan pada daerah momen tumpuan maximum pada balok precast dengan menggunakan pelat siku sebagai material sambungnya. Dengan adanya penelitian tersebut jelas sekali akan mempermudah dan meminimalkan biaya dalam pelaksanaan kontruksi bangunan. Namun faktor terpenting yang harus diperhatikan dari semua penelitian adalah faktor kekuatan dan daktilitas elemen struktur (strength and ductility).Penelitian ini menghasilkan suatu kemudahan dalam sistim erection di lapangan. Pada sambungan tersebut dilakukan grouting dengan percampuran antara bahan grouting nonshrinkage (tidak susut) dengan coarse aggregate (agregat kasar). Percampuran tersebut dilakukan dengan prosentase agregat kasar 50\% berat Sika Grout 215. Penelitian ini merupakan pengembangan dari penelitian sebelumnya. Penelitian ini menghasilkan suatu bentuk kemudahan dalam pelaksanaan kontruksi bangunan (erection) yang tidak meninggalkan kekuatan (strength) dan daktilitas dari balok tersebut ${ }^{(1,2,3,4)}$.

\section{Teori}

\section{Tension Splices}

Kerusakan pada beton ( splitting ) yang berbahaya pada sambungan sistim splices adalah pada daerah ujung-ujung dari sambungan tulangan tersebut ${ }^{(2,3,4)}$. Stock telah melakukan penelitian dan menyatakan bahwa gaya transfer terbesar berada pada daerah ujung-ujung sambungan splices tersebut. ACI (American Concrete Institute) memberikan syarat-syarat untuk sambungan splices.

\section{Compresion Splices}

Besarnya gaya yang terjadi pada daerah compression splices tidak sama dibandingkan dengan kasus pada tension splices. Dimana gaya yang terjadi pada tension splices akan lebih besar dibandingkan dengan compression splices. Perpanjangan tulangan splices pada daerah compression splices dapat diambil sebesar ld atau 0,07.fy.db untuk fy 420 Mpa atau kurang ${ }^{(1,2,3,4)}$.

\section{Grouting}

Grouting pada balok precast dengan sistim bonded nonprestressed memegang peranan sangat penting dalam menciptakan kekuatan lentur dan geser. Ikatan antara beton dan tulangan disini sangat dipengaruhi oleh jenis bahan grouting tersebut. Begitu pula dengan bahan ikatan antara beton lama dan beton baru.Peneliti menggunakan bahan grouting produksi SIKA yaitu SikGrout 215 dengan spesifikasi sebagai berikut:

- Compressive Strength 712 $\mathrm{Kg} / \mathrm{cm} 2$

- $\quad$ Flexural Strength $\quad 58,6$ $\mathrm{Kg} / \mathrm{cm} 2$

\section{Metode Penelitian}

\section{Tempat Penelitian dan Alat Yang Digunakan}

Penelitian ini dilakukan di laboratorium Kontruksi dan Bahan Politeknik Negeri Jakarta, dengan menggunakan alat - alat slump test dan universal testing machine (UTM )

\section{Bahan-Bahan dan prototype}

Bahan-bahan yang digunakan dalam penelitian ini adalah beton dengan mutu fc'48,16 Mpa,besi beton diameter 13 $\mathrm{mm}$ dan besi beton diameter $8 \mathrm{~mm}$

Prototype dari benda uji adalah benda uji berbentuk balok dengan panjang 150 $\mathrm{cm}$,lebar $15 \mathrm{~cm}$ dan tinggi balok $30 \mathrm{~cm}$. Benda uji ini didesain dengan menggunakan tulangan diameter $13 \mathrm{~mm}$ dengan fy 360 Mpa untuk tulangan 
lenturnya dan diameter $8 \mathrm{~mm}$ dengan fy 240 Mpa untuk tulangan gesernya. Untuk mutu beton digunakan mutu beton fc'48,16 Mpa. Jumlah benda uji yang dilakukan dalam penelitian ini dapat dilihat pada tabel 1 di bawah ini.

Tabel 1. Jumlah Benda Uji

\begin{tabular}{llccl}
\hline No & Benda Uji & $\begin{array}{c}\text { Jum. } \\
\text { Bh }\end{array}$ & $\begin{array}{c}\text { Tul. } \\
\text { Utama }\end{array}$ & $\begin{array}{l}\text { Tul. } \\
\text { Ges. }\end{array}$ \\
\hline 1 & $\begin{array}{l}\text { Konvensional } \\
1 \text { dan 2 }\end{array}$ & 2 & 3 D 13 & $\mathrm{d} 8$ \\
\hline 2 & $\begin{array}{l}\text { Precast 3 dan } \\
4\end{array}$ & 2 & 3 D 13 & $\mathrm{d} 8$ \\
\hline
\end{tabular}

Table 2 adalah perbandingan campuran berat agregat terhadap berat SIKA Grout 215.

Tabel 2. Camp Agregat Kasar dan Sika Grout 215

\begin{tabular}{lll}
\hline No & Campuran & $\begin{array}{l}\text { Prosen berat Agregat } \\
\text { terhadap berat } \\
\text { SIKA Grout 215 }\end{array}$ \\
\hline 1 & Campuran & $50 \%$ \\
\hline
\end{tabular}

Benda uji nomor 3 dan 4 adalah benda uji balok precast sedangkan benda uji nomor 1 dan 2 adalah benda uji balok konvensional, di mana balok ini sebagai pembanding dalam menentukan kekuatan dan defleksi balok benda uji nomor 3 dan 4 .

Untuk lebih jelasnya dapat dilihat gambar 1 prototype balok sebagai berikut:

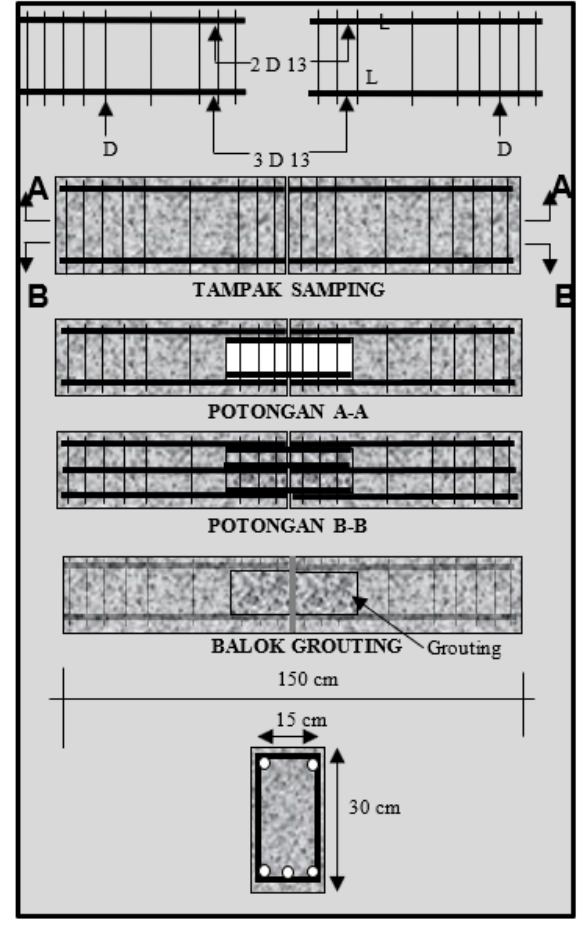

Gambar 1. Prototype Benda Uji

\section{Metode Pengujian}

Untuk metoda pengujian ini mengacu pada peraturan ASTM C78-02, peneliti menggunakan alat Universal Testing Machine dengan kondisi pembebanan seperti gambar 2 di bawah ini.

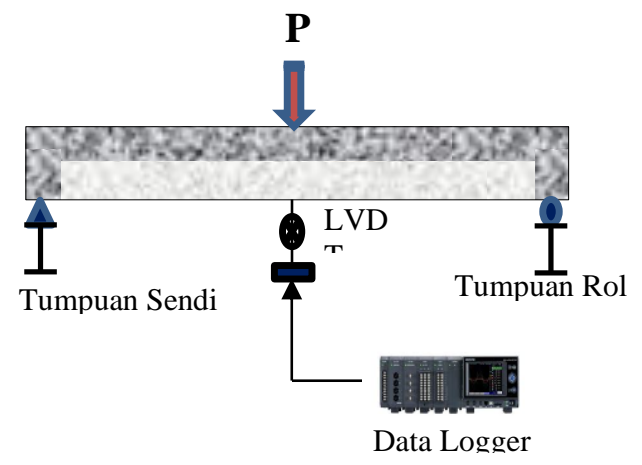

Gambar 2. Pembebanan balok

Untuk pengujian lentur, beban yang akan diaplikasikan pada benda uji balok baik precast maupun konvensional menumpu pada satu itik di tengah bentang balok dengan media besi bulat pejal.

Beban diaplikasikan sampai kondisi balok mencapai keruntuhan. Data 
maksimum beban dan lendutan yang terjadi akan di catat sesuai kode balok masing masing.

Dari kedua data tersebut akan diambil suatu kesimpulan akhir mngenai performa balok baik precast maupun konvensional.

\section{Hasil dan Pembahasan}

\section{Hasil Uji Silinder}

Adapun hasil dari pengetesan umur 28 hari seperti tabel 3 sebagai berikut:

\begin{tabular}{|c|c|c|c|c|}
\hline \multirow[t]{2}{*}{ No } & \multirow{2}{*}{$\begin{array}{c}\text { Benda } \\
\text { Uji }\end{array}$} & \multirow{2}{*}{$\begin{array}{c}\mathbf{f c}^{\prime} \\
\mathrm{Mpa}\end{array}$} & \multirow{2}{*}{$\begin{array}{c}\begin{array}{c}\text { Rata } \\
\text { fc' }\end{array} \\
\text { Mpa }\end{array}$} & \multirow{2}{*}{$\begin{array}{c}\text { Ec } \\
\mathrm{Mpa}\end{array}$} \\
\hline & & & & \\
\hline 1 & Kon.1A & 45,2 & 46,7 & $32.121,7$ \\
\hline 2 & Kon.1B & 48,1 & & \\
\hline 3 & Kon.2A & 50,9 & 48,4 & $32.700,5$ \\
\hline 4 & Kon 2B & 45,8 & & \\
\hline 5 & Pre.3A & 50,3 & 47,8 & $32.508,7$ \\
\hline 6 & Pre.3B & 45,2 & & \\
\hline 7 & Pre.4A & 47,5 & 49,6 & $33.128,0$ \\
\hline 8 & Pre.4B & 51,8 & & \\
\hline 9 & Grout. & 52,6 & 52,6 & $34.104,6$ \\
\hline
\end{tabular}

Rata rata kuat tekan dari 8 benda uji silinder adalah 48,16 Mpa dan untuk hasil uji yield strength dari tulangan didapat fy $360 \mathrm{Mpa}$

\section{Hasil Uji Lentur Benda Uji Konvensional dan Precast}

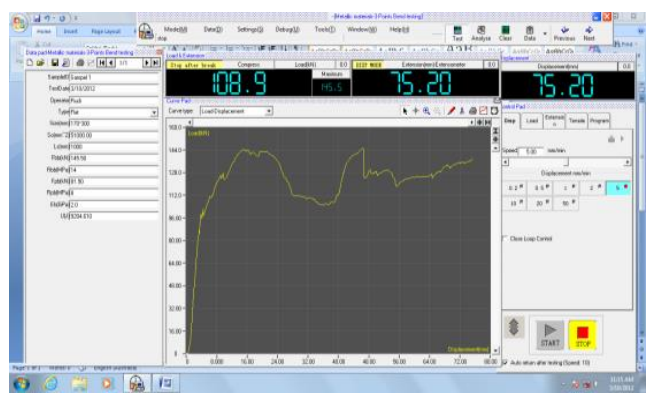

Gambar 3. Grafik Pembebanan Benda Uji Konvesional 1

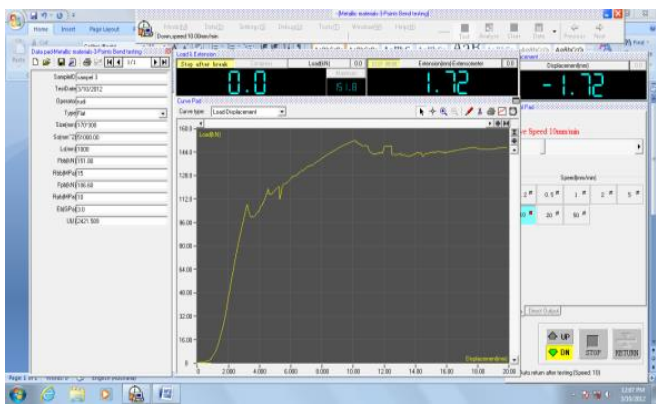

Gambar 4. Grafik Pembebanan Benda Uji Konvesional 2

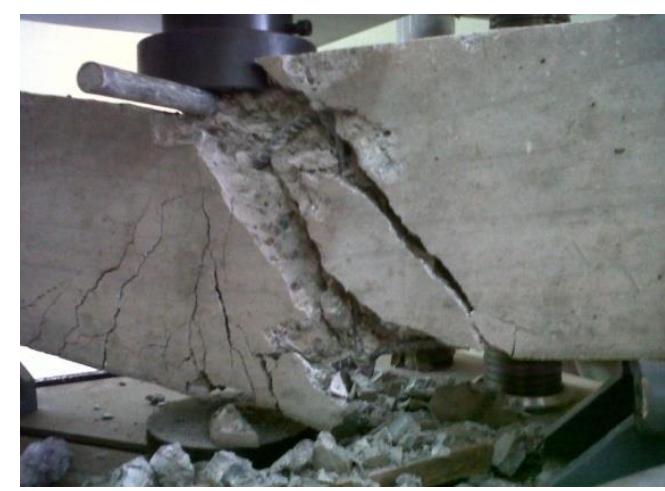

Gambar 5. Keruntuhan Benda Uji Konvensional 1

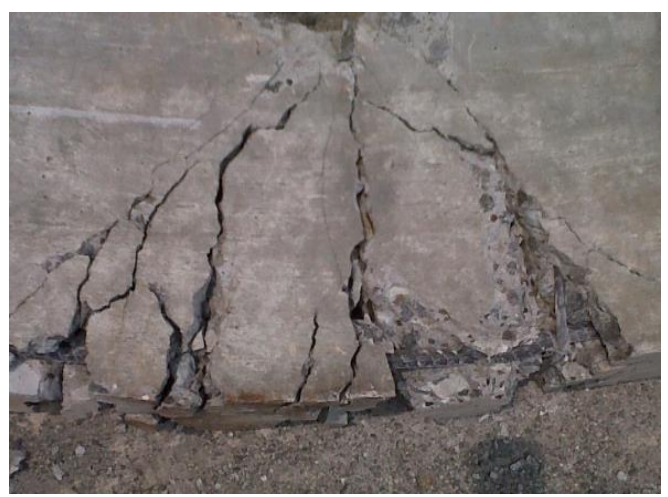

Gambar 6. Keruntuhan Benda Uji Konvensional 2

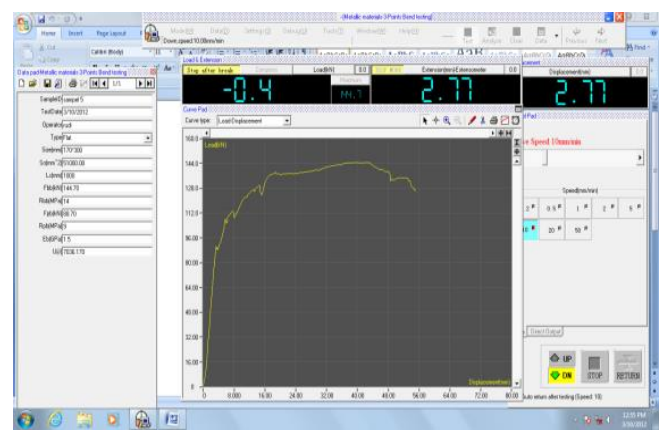


Gambar 7. Grafik Pembebanan Benda Uji Precast 1

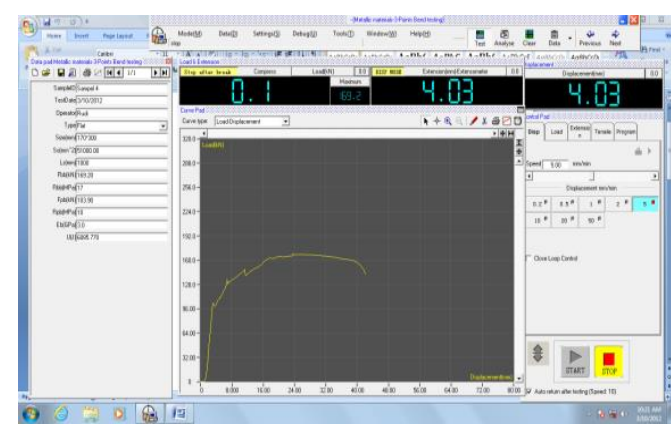

Gambar 8. Grafik Pembebanan Benda Uji Precast 2

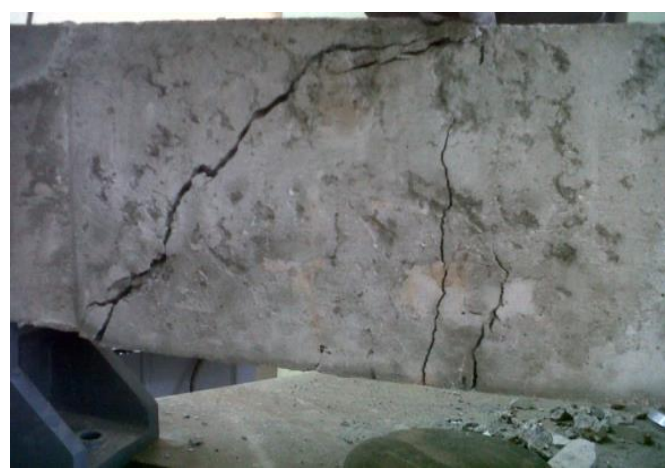

Gambar 9. Keruntuhan Benda Uji Precast 1

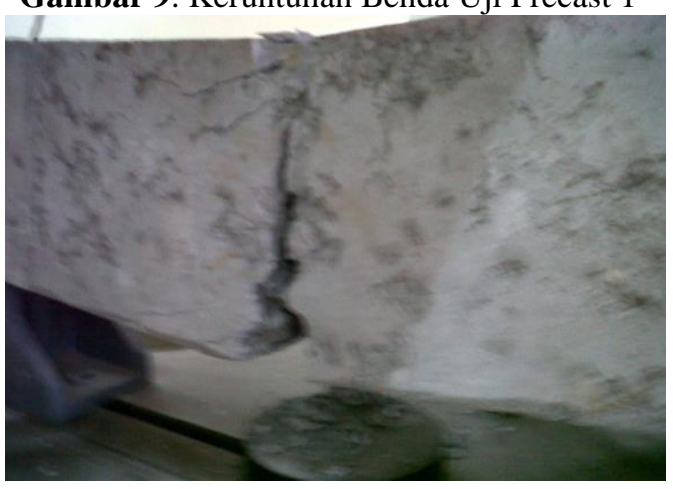

Gambar 10. Keruntuhan Benda Uji Precast 2

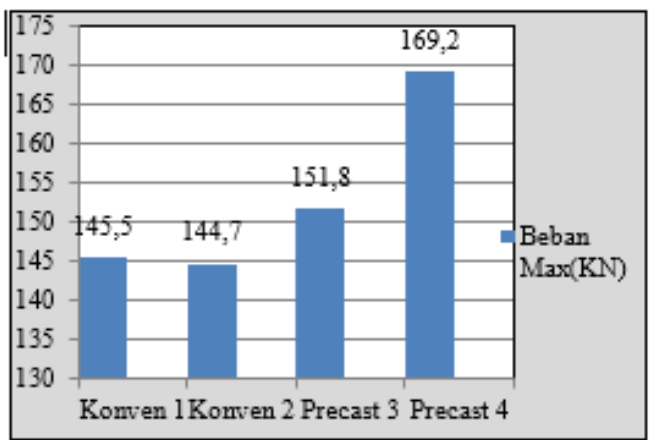

Gambar 11. Grafik Beban Max Benda Uji Konvesional dan Precast

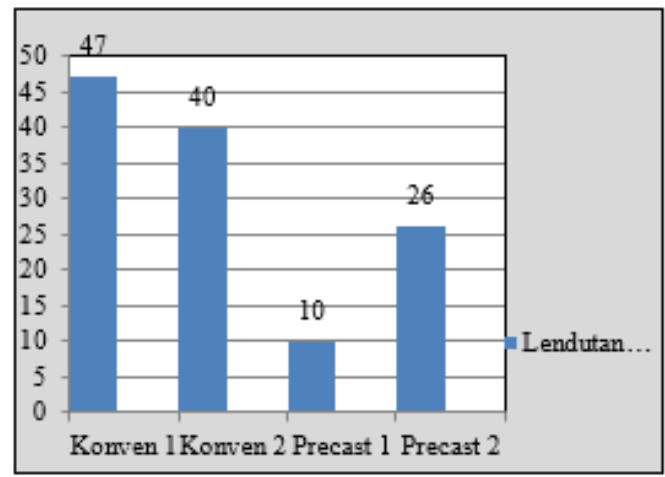

Gambar 12. Grafik Lendutan Benda Uji Konvensional dan Precast

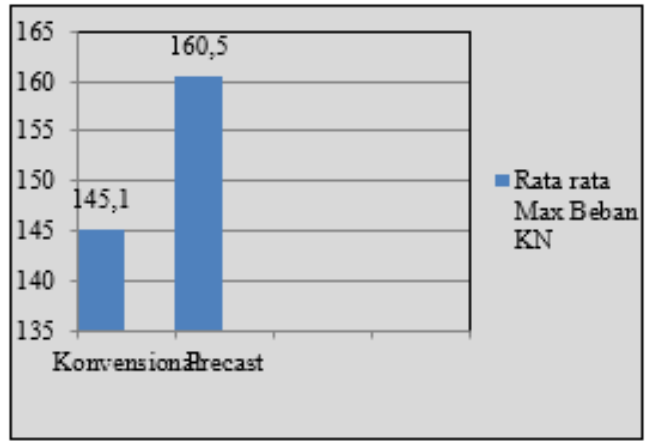

Gambar 13. Grafik Rata Beban Max Benda Uji Konvensional dan Precast

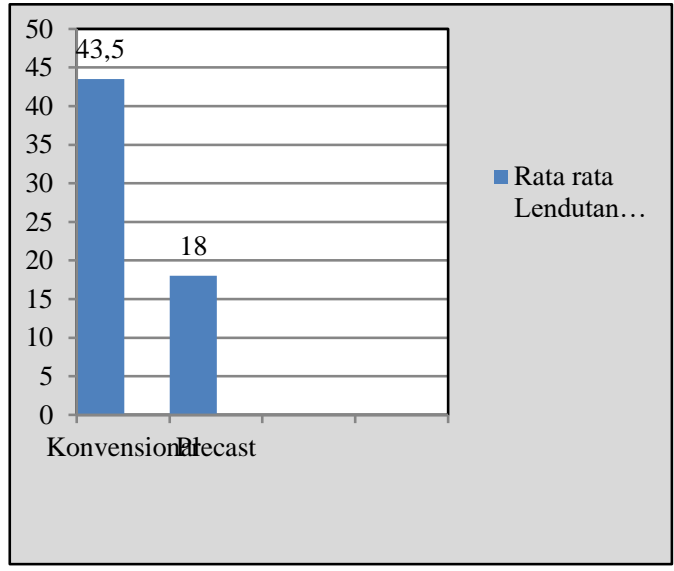

Gambar 14. Grafik Rata-rata Lendutan Max Benda Uji Konvensional dan Precast 


\section{Pembahasan}

Pembahasan dimulai dari benda uji balok konvensional kemudian tahap selanjutnya ke benda uji balok precast. Pembahasan mengenai performa yang dihasilkan oleh kedua sistim balok tersebut, mulai dari masing-masing balok kemudian performa balok secara keseluruhan.

\section{Benda uji balok konvenional 1}

Dari hasil pembebanan yang dihasilkan (gambar 3), terlihat performa balok dengan grafik non linear setelah leleh awal tercapai. Awal leleh terjadi pada saat pembebanan lebih kurang $96 \mathrm{KN}$. Setelah awal leleh tercapai, performa balok tidak stabil sampai mencapai regangan maksimal beton pada saat pembebanan maksimal tercapai sebesar 145,5 KN (gambar 5).

Displacement yang terjadi pada saat awal leleh adalah $4 \mathrm{~mm}$, dan pada saat beban maksimal tercapai lendutan maksimal adalah $47 \mathrm{~mm}$.

Dari gambar yang ada terlihat tercapainya crushing beton pada daerah tekan, artinya adanya kerusakan yang terjadi baik pada daerah tekan maupun pada daerah tarik dari balok konvensional tersebut (balance).

\section{Benda uji balok konvenional 2}

Dari hasil pembebanan yang dihasilkan (gambar 4), terlihat performa balok dengan grafik non linear setelah leleh awal tercapai. Awal leleh terjadi pada saat pembebanan lebih kurang $92 \mathrm{KN}$. Setelah awal leleh tercapai, performa balok kurang stabil sampai mencapai regangan maksimal beton pada saat pembebanan maksimal tercapai sebesar 144,7 KN (gambar 6).

Displacement yang terjadi pada saat awal leleh adalah $3 \mathrm{~mm}$, dan pada saat beban maksimal tercapai lendutan maksimal adalah $40 \mathrm{~mm}$.
Dari gambar yang ada terlihat tercapainya sedikit crushing beton pada daerah tekan, artinya adanya kerusakan yang terjadi baik pada daerah tekan maupun pada daerah tarik dari balok konvensional tersebut (balance).

\section{Benda Uji Balok Precast 1}

Dari hasil pembebanan yang dihasilkan (gambar 7), terlihat performa balok dengan grafik non linear setelah leleh awal tercapai. Awal leleh terjadi pada saat pembebanan lebih kurang $108 \mathrm{KN}$. Setelah awal leleh tercapai, performa balok kurang stabil sampai mencapai regangan maksimal beton pada saat pembebanan maksimal tercapai sebesar 151,8 KN (gambar 9).

Displacement yang terjadi pada saat awal leleh adalah 3,5 $\mathrm{mm}$, dan pada saat beban maksimal tercapai lendutan maksimal adalah $10 \mathrm{~mm}$.

Dari gambar yang ada terlihat tidak terjadi crushing beton pada daerah tekan, artinya tidak adanya kerusakan yang terjadi pada daerah tekan akan tetapi kerusakan terjadi pada daerah tarik dari balok precast tersebut ( underreinforce ).

\section{Benda Uji Balok Precast 2}

Dari hasil pembebanan yang dihasilkan (gambar 8), terlihat performa balok dengan grafik non linear setelah leleh awal tercapai. Awal leleh terjadi pada saat pembebanan lebih kurang $104 \mathrm{KN}$. Setelah awal leleh tercapai, performa balok tetap stabil sampai mencapai regangan maksimal beton pada saat pembebanan maksimal tercapai sebesar 169,2 KN (gambar 10).

Displacement yang terjadi pada saat awal leleh adalah $3 \mathrm{~mm}$, dan pada saat beban maksimal tercapai lendutan maksimal adalah $26 \mathrm{~mm}$.

Dari gambar yang ada terlihat sedikit terjadi crushing/spliting beton pada daerah tekan, artinya tidak adanya sedikit kerusakan pada daerah tekan 
akan tetapi kerusakan terjadi pada daerah tarik dari balok precast tersebut (underreinforce ).

Dari hasil analisis secara keseluruhan dapat dikatakan performa balok precast lebih baik dibandingkan dengan balok konvensional.

\section{Kesimpulan}

1. Dari hasil yang dicapai oleh seluruh benda uji dihasilkan bahwa kekuatan atau performa balok precast dengan sambungan sistim double splices middle wet joint menunjukkan performa yang lebih baik dibandingkan dengan balok konvensional

2. Lendutan yang dihasilkan oleh balok konvensional menunjukan lebih besar dibandingkan dengan lendutan yang dihasilkan oleh balok precast dengan sambungan sistim double splices middle wet joint

\section{Daftar Pustaka}

[1] Nadim,M and Akthem 2008. Structural Concrete theory and design, John Wiley and Sons, USA

[2] ACI Committee 318 ( 2011 ), Building Code Requirments for Structure and Commentary,American Concrete Institute, Detroit

[3] SNI 03-2847-2012, Standar Nasional Indonesia ,Tata Cara Perhitungan Struktur Beton Untuk Bangunan Gedung, Bandung, 2012

[4] Rodríguez. dan Torres M, Summer 2013 , "Seismic Behavior of type of welded precast concrete beam- colum connection, PCI Journal Paper,Vol.58, Issue: 3, Page number: 81-94
[5] Ugur Ersoy and Tankut Tugrul, July-August 1993," Precast Concrete Members with Welded Plate Connections Under Reversed Cyclic Loading “ PCI Jurnal Paper, Volume 38, Issue: 4, Page number: 94-100

[6] Andrea Belleri, Paolo Riva,2012, "Seismic performance and retrofit of precast concrete grouted sleeve connections", Volume: 57, Issue: 1, Page number: 97-109

[7] Mario E. Rodríguez, Miguel Torres-Matos,2013, "Seismic behavior of a type of welded precast concrete beam-column connection", Volume: 58, Issue: 3, Page number: 81-94

[8] Ameli,J dan Park,Joel E, March April 2015," Seismic evaluation of grouted splice sleeve connections for reinforced precast concrete column-to-cap beam joints in accelerated bridge construction", PCI Journal Paper, Volume: 60 Issue: 2 Page number: 80 - 103

[9] Nabi Goudarzi, Yasser Korany, March-April 2016," Characterization of the shear behavior of Z-shaped steel plate connectors used in insulated concrete panels", PCI Journal Paper, Volume: 61,Issue: 2, Page Number: 23-37

[10] Elide Pantoli dan Tara C. Hutchinson, July-August 2016," Seismic-drift-compatible design of architectural precast concrete cladding: Tieback connections and corner joints", PCI Journal Paper, Volume: 61, Issue: 4, Page Numbers: 38-52

[11] Hatem M. Seliem dan Lining Ding, September-October 2016," Use of a carbon-fiber-reinforced polymer grid for precast concrete 
A.Rudi Hermawan, Eka SM, Performa Sambungan Balok...

piles", PCI Journal Paper,Volume:

61, Issue: 5, Page Number: 37-48 